\title{
A Shock Tube Study of the Branching Ratios of Propene + OH Reaction
}

\author{
Jihad Badra ${ }^{1,2}$, Fethi Khaled ${ }^{1}$, Binod Raj Giri ${ }^{1}$ and Aamir Farooq ${ }^{{ }^{*}}$ \\ ${ }^{1}$ Clean Combustion Research Center, Division of Physical Sciences and Engineering, King \\ Abdullah University of Science and Technology (KAUST), Thuwal 23955, Saudi Arabia \\ ${ }^{2}$ Saudi Aramco Research and Development Center, Fuel Technology R\&D Division, Dhahran \\ 31311, Saudi Arabia \\ *Corresponding Author - Email: aamir.farooq@kaust.edu.sa, Phone: +966544700621
}




\begin{abstract}
Absolute rate coefficients for the reaction of $\mathrm{OH}$ radical with propene $\left(\mathrm{C}_{3} \mathrm{H}_{6}\right)$ and five deuterated isotopes, propene-1-D1 $\left(\mathrm{CDHCHCH}_{3}\right)$, propene-1,1-D2 $\left(\mathrm{CD}_{2} \mathrm{CHCH}_{3}\right)$, propene112-D3 $\left(\mathrm{CD}_{2} \mathrm{CDCH}_{3}\right)$, propene-3,3,3-D3 $\left(\mathrm{CH}_{2} \mathrm{CHCD}_{3}\right)$, and propene-D6 $\left(\mathrm{C}_{3} \mathrm{D}_{6}\right)$, were measured behind reflected shock waves over the temperature range of $818-1460 \mathrm{~K}$ and pressures near 1 atm. The reaction progress was followed by monitoring $\mathrm{OH}$ radical near $306.7 \mathrm{~nm}$ using UV laser absorption. Kinetic isotope effects in the measured rate coefficients are discussed and rationalized for the site-specific $\mathrm{H}$ abstraction by $\mathrm{OH}$ radical. The first experimental measurements for the branching ratio of the title reaction are reported and compared with transition state theory calculations. The allylic $\mathrm{H}$-atom abstraction of propene by $\mathrm{OH}$ radicals was found to be the most dominant reaction pathway followed by propen-1-yl and propen-2-yl channels over the entire temperature range of this study. The derived Arrhenius expressions for various site-specific rate coefficients over $818-1442 \mathrm{~K}$ are (the subscript in the rate coefficient identifies the position of $\mathrm{H}$ or $\mathrm{D}$ atom according to the IUPAC nomenclature of alkenes):
\end{abstract}

$$
\begin{aligned}
& k_{3, \mathrm{H}}=2.32 \times 10^{-11} \exp (-2341 \mathrm{~K} / T) \mathrm{cm}^{3} \text { molecule }^{-1} \mathrm{~s}^{-1} \\
& k_{3, \mathrm{D}}=1.96 \times 10^{-11} \exp (-2420 \mathrm{~K} / T) \mathrm{cm}^{3} \text { molecule }^{-1} \mathrm{~s}^{-1} \\
& k_{1, \mathrm{H}}=1.39 \times 10^{-11} \exp (-2270 \mathrm{~K} / T) \mathrm{cm}^{3} \text { molecule }^{-1} \mathrm{~s}^{-1} \\
& k_{1, \mathrm{D}}=1.95 \times 10^{-11} \mathrm{exp}(-2868 \mathrm{~K} / T) \mathrm{cm}^{3} \text { molecule }^{-1} \mathrm{~s}^{-1} \\
& k_{2, \mathrm{H}}=7.2 \times 10^{-12} \exp (-2282 \mathrm{~K} / \mathrm{T}) \mathrm{cm}^{3} \text { molecule }^{-1} \mathrm{~s}^{-1} \\
& k_{2, \mathrm{D}}=7.69 \times 10^{-12} \exp (-2575 \mathrm{~K} / T) \mathrm{cm}^{3} \text { molecule }^{-1} \mathrm{~s}^{-1}
\end{aligned}
$$

Keywords: Propene; hydroxyl radicals; rate coefficients; shock tube; site-specific rates, transition state theory; branching ratio. 


\section{Introduction}

Propene $\left(\mathrm{C}_{3} \mathrm{H}_{6}\right)$ is an important intermediate species in many hydrocarbon combustion systems. Propene is a significant component of liquefied petroleum gas (LPG) which can be in surplus in future due to the recent shale gas "revolution". Propene is formed by the decomposition of alkyl radicals during the oxidation of alkanes. It may also serve as a prototype alkene fuel and is the simplest allylic system. For combustion modelling of a fuel like LPG that contains many different components, it is important to understand the underlying chemistry of the individual fuels. Therefore, understanding the propene oxidation pathways is very important in the hierarchical development of detailed chemical kinetic models. Recently, Taatjes et. al. ${ }^{2}$ detected enols in substantial amount in a wide range of hydrocarbon flames and suggested that the oxidation of ethylene by $\mathrm{OH}$ radical is the dominant source of enol formation. In ethene flames, the oxidation of ethene by $\mathrm{OH}$ radicals was found to dominate the ethenol production ${ }^{3}$. The overall chemistry of $\mathrm{OH}+$ propene reaction system, in particular its role to the formation of enols, has recently been the subject of research interest for various groups ${ }^{2,4-6}$. Propene oxidation can also contribute to soot production (and other pollutant formation) ${ }^{7}$. Strategies for mitigating pollutant formation in advanced combustion systems depend, in part, on the oxidation of alkenes such as propene.

The overall rate constants for the reaction of propene with hydroxyl radical have been measured experimentally by several groups ${ }^{8-18}$. Among these, only a few studies were carried out at combustion relevant temperatures. Smith et. $a l^{9}$ measured the total rate coefficients over the temperature range of 960 - $1210 \mathrm{~K}$ using laser photolysis/laser-induced fluorescence technique. They observed a pronounced positive $T$-dependence of the rate coefficients and suggested that a direct endothermic channel prevails at high temperatures. Such behaviour for the reaction of propene with $\mathrm{OH}$ radicals was in contrast to that observed at temperatures below $500 \mathrm{~K}$, where the rate coefficients show a negative $T$-dependence ${ }^{9}$. Using the same 
technique as Smith et. $a l^{9}$, Tully and Goldsmith ${ }^{13}$ reported the rate coefficients over the temperature range of $293-893 \mathrm{~K}$. Though the results of Smith et al ${ }^{9}$. suggest a stronger $T$ dependence of the total rates than that of Tully and Goldsmith ${ }^{13}$, the extrapolated value $(\approx$ $9 \times 10^{-12} \mathrm{~cm}^{3}$ molecule $\mathrm{s}^{-1}$ ) from the latter agrees well with the former group at $1200 \mathrm{~K}$. Bott and Cohen ${ }^{18}$ studied the reactions of hydroxyl radical with several organic species near 1200 $\mathrm{K}$ and 1 atm using shock tube/UV absorption technique. Their reported value for propene + $\mathrm{OH}$ reaction was found to be about 1.8 times larger than either of Smith et $a l^{9}$. or the extrapolated value of Tully and Goldsmith ${ }^{13}$. The kinetic analysis of Yetter and Dryer ${ }^{19}$ resulted in a value of $1.3 \times 10^{-11} \mathrm{~cm}^{3}$ molecule $\mathrm{s}^{-1}$ at $1020 \mathrm{~K}$ which is 2.7 times larger than that of Smith et $a l^{9}$. In a recent experimental study, Vasu et $a l^{17}$. measured the rate constant in a shock tube using laser absorption technique over $890-1366 \mathrm{~K}$ and pressures near $2.3 \mathrm{~atm}$. Their values for the total rate coefficients showed an excellent agreement with the earlier measurements by Bott and Cohen ${ }^{18}$ and Tully and Goldsmith ${ }^{13}$. The agreement with the data from Tully and Goldsmith ${ }^{13}$ is applicable only for their intermediate temperature measurements and does not apply on the extrapolation to the high temperature region. However, their rate data were lower than that of Yetter and Dryer ${ }^{19}$ and higher compared to Smith et. $a l^{9}$ data at the corresponding temperatures.

Several detailed theoretical studies ${ }^{4-6,20-24}$ have been carried out for the energetics of propene and $\mathrm{OH}$ reaction. In a recent paper, Zádor et $a l^{5}$. employed RQCISD(T)/ccpV $\propto Z / / B 3 L Y P / 6-311++G(d, p)$ quantum chemical calculations combined with RRKM Master Equation (ME) methodology to investigate the branching ratios for various channels that are accessible on $\mathrm{C}_{3} \mathrm{H}_{7} \mathrm{O}$ potential energy surface. Huynh et al explored the detailed potential energy surface using $\operatorname{CCSD}(\mathrm{T}) / \mathrm{cc}-\mathrm{pVDZ} / \mathrm{B} 3 \mathrm{LYP} / \mathrm{cc}-\mathrm{pVTZ} a b$ initio method and further carried out kinetic analyses for the branching ratios of various products using ME methodology. The primary focus in their study was to provide kinetic information 
for the enol formation channel. In a similar work, Zhou et $a .^{4}$ computed the detailed potential energy surface at PMP2/aug-cc-PVQZ//MP2/cc-PVTZ level of theory for the addition and abstraction reactions of propene and $\mathrm{OH}$ radical. These theoretical studies showed that the $\mathrm{OH}$ radical adds to the double bond of propene like it does in any other olefin $+\mathrm{OH}$ reaction and that the dominant reaction pathways change with temperature and pressure. The studies of Zádor et al. ${ }^{5}$ and Huynh et al. ${ }^{6}$ found that the $\mathrm{H}$ abstraction channel is dominant ( $(290 \%)$ over the addition channel at high temperatures $(T \geq 600 \mathrm{~K})$. Their total rate constants are in excellent agreement with the recent high-temperature experimental work of Vasu et al. ${ }^{17}$ and with the recommendation by Tsang et $a .^{25}$. The computed values of Zhou et al. ${ }^{4}$, however, differed from other studies in both the magnitude of the rate coefficients and the branching ratios. For example, their reported value of the rate coefficients of the abstraction channel were about one order of magnitude lower than that of Huynh et al. ${ }^{6}$, Zádor et al. ${ }^{5}$ and Vasu et al. ${ }^{17}$. Although the qualitative features of the Zhou et al. ${ }^{4}$ potential energy surface of $\mathrm{C}_{3} \mathrm{H}_{7} \mathrm{O}$ were similar to other theoretical studies, significant quantitative differences were found in the computed potential energy surface of $\mathrm{C}_{3} \mathrm{H}_{7} \mathrm{O}$ that resulted in the discrepancies in the branching ratios of various channels. At high temperatures, all studies predicted that the abstraction reaction leading to allyl radical and $\mathrm{H}_{2} \mathrm{O}$ is by far the most dominant abstraction channel, whereas the other two abstraction channels leading to propen-1-yl and propen-2-yl are found to be minor. However, the branching ratio of propen-1-yl radicals reported by Zhou et $a l .{ }^{4}$ is significantly larger than that of Zádor et al. ${ }^{5}$. Therefore, large discrepancies still exists in the literature for the branching ratios of the title reaction and experimental determination of the branching ratios are not available thus far.

In this work, we present the first detailed experimental study for the elucidation of $\mathrm{H}$ atom abstraction branching ratios for the reaction of propene with $\mathrm{OH}$ radicals. Experiments are carried out using a shock tube and UV laser absorption of $\mathrm{OH}$ at temperatures ranging 
from $818 \mathrm{~K}$ to $1460 \mathrm{~K}$ at pressures near $1 \mathrm{~atm}$. The rate coefficients of six propene isotopes with $\mathrm{OH}$ were measured and the data are rationalized to determine the site-specific abstraction rates. The following reactions are investigated and their rate coefficients are reported:

$$
\begin{aligned}
& \mathrm{C}_{3} \mathrm{H}_{6}+\mathrm{OH} \rightarrow \text { Products } \\
& \mathrm{CDHCHCH}_{3}+\mathrm{OH} \rightarrow \text { Products } \\
& \mathrm{CD}_{2} \mathrm{CHCH}_{3}+\mathrm{OH} \rightarrow \text { Products } \\
& \mathrm{CD}_{2} \mathrm{CDCH}_{3}+\mathrm{OH} \rightarrow \text { Products } \\
& \mathrm{CH}_{2} \mathrm{CHCD}_{3}+\mathrm{OH} \rightarrow \text { Products } \\
& \mathrm{C}_{3} \mathrm{D}_{6}+\mathrm{OH} \rightarrow \text { Products }
\end{aligned}
$$

\section{Experimental Methods}

Experiments were carried out in a turbo-pumped, high purity, stainless steel shock tube facility over a temperature range of $818 \mathrm{~K}$ to $1460 \mathrm{~K}$ and pressure of about $1 \mathrm{~atm}$. The shock tube and $\mathrm{OH}$ laser diagnostic have been detailed previously ${ }^{26-28}$ and only a brief description is given here. Both the driver and driven sections of our shock tube are $9 \mathrm{~m}$ long with an inner diameter of $14.2 \mathrm{~cm}$. The length of the driver section can be varied depending on the required test times. For the experiments reported here, a shorter $(\sim 3 \mathrm{~m})$ driver section was used to achieve $2 \mathrm{~ms}$ of uniform test time. The incident shock speed is measured using a series of five piezoelectric PCB pressure transducers that are placed over the last $1.3 \mathrm{~m}$ of the driven section of the shock tube. Temperatures and pressures behind reflected shock waves are calculated from the measured incident shock speed and standard shock-jump relations. Uncertainties in the measured shock velocity $(\approx 0.1-0.2 \%)$ will translate into the uncertainties in the calculated reflected shock temperatures and pressures of about $0.7 \%$ and $1 \%$, respectively. The shock tube facility is equipped with a magnetically-stirred 24-litre 
mixing vessel and a well-furnished mixing manifold for the preparation of mixtures. A double-dilution process was utilized to prepare accurate mixtures ${ }^{27}$. The $\mathrm{OH}$ laser diagnostic and a Kistler 603B piezoelectric pressure transducer are located at a test section $2 \mathrm{~cm}$ from the driven section endwall. Ultraviolet light for $\mathrm{OH}$ absorption is generated by the external frequency doubling of red light $(614 \mathrm{~nm})$ produced by a ring-dye cw laser which is pumped by a $10 \mathrm{~W}$ green laser $(532 \mathrm{~nm})$. In the current experiments, UV light is tuned to the center $(306.6868 \mathrm{~nm})$ of the well-characterized R1(5) absorption line in the $\mathrm{OH} \mathrm{A}-\mathrm{X}(0,0)$ absorption band. A common-mode-rejection scheme is used here which gives a detection limit of about $0.2 \mathrm{ppm}$ at $1400 \mathrm{~K}$ and $1 \mathrm{~atm}$, assuming a minimum detectable absorbance of $0.1 \%$. The $\mathrm{OH}$ mole fraction is calculated from Beer-Lambert law, $I / I_{\mathrm{o}}=\exp \left(-k_{\mathrm{OH}} X_{\mathrm{OH}} P L\right)$, where $I$ and $I_{\mathrm{o}}$ are the transmitted and incident laser intensities, $k_{\mathrm{OH}}$ is the $\mathrm{OH}$ absorption coefficient, $X_{\mathrm{OH}}$ is the $\mathrm{OH}$ mole fraction, $P$ is the total pressure (atm), and $L$ is the path length $(14.2 \mathrm{~cm})$. Estimated uncertainty in the measured $\mathrm{OH}$ mole fraction $\left(X_{\mathrm{OH}}\right)$ is approximately \pm $3 \%$ which is mainly due to the uncertainty in the reflected-shock temperature and $\mathrm{OH}$ absorption coefficient. Experimental data are recorded at a sampling rate of $2.5 \mathrm{MHz}$ using a high-resolution (14 bit) data acquisition system.

Hydroxyl radicals were produced by rapid thermal decomposition of tert-butyl hydroperoxide (TBHP), which is known to be a clean $\mathrm{OH}$ precursor and has been validated in many studies ${ }^{17,29,30}$. A 70\% TBHP in water solution was obtained from Sigma Aldrich. Propene $(\geq 99.99 \%)$, argon $(99.999 \%)$, and helium $(99.999 \%)$ were purchased from AH Gases. Propene-1-d1 ( $\geq 98 \%)$, propene-1,1-d2 ( $\geq 99.3 \%)$, propene 2-d1 ( $\geq 98 \%)$, propene3,3,3-d3 ( $\geq 99.8 \%)$, and propene-d6 ( $\geq 99.8 \%)$ were supplied by CDN Isotopes. Several reflected-shock experiments were conducted for each fuel and the concentrations of reactants (fuel, TBHP) were chosen carefully based on sensitivity analysis while maintaining pseudofirst-order conditions. 


\section{Results and Discussion}

\subsection{High-Temperature Measurements of Propene $+\mathrm{OH} \rightarrow$ Products}

High-temperature rate constant measurements for the reaction of $\mathrm{OH}$ with six deuterated isotopes of propene are described in this section. A mixture of $312 \mathrm{ppm}$ propene $\left(\mathrm{C}_{3} \mathrm{H}_{6}\right), 19 \mathrm{ppm}$ TBHP (60 ppm of water), and balance Ar was shock-heated to a range of post-shock temperatures $\left(T_{5}=853-1442 \mathrm{~K}\right)$ and pressures $\left(P_{5} \approx 1 \mathrm{~atm}\right)$ to measure the overall reaction rate coefficients for propene $+\mathrm{OH} \rightarrow$ products. A raw trace of the measured $\mathrm{OH}$ time-history at $1101 \mathrm{~K}$ and $1.37 \mathrm{~atm}$ is presented in Fig. 1. Experimentally measured $\mathrm{OH}$ profiles are fitted using the JetSurf 1.0 mechanism $^{31}$, as the base mechanism, with tert-butyl hydroperoxide (TBHP) reactions added from Pang et al ${ }^{29}$. The initial TBHP concentration for simulated profiles is taken from the experimental $\mathrm{OH}$ yield. The best-fit for $\mathrm{OH}$ profile was obtained for a $k_{\mathrm{I}}$ value of $1.24 \times 10^{-11} \mathrm{~cm}^{3}$ molecule $\mathrm{s}^{-1}$ and the effect of $50 \%$ deviations from this value is also presented in Fig. 1. The measured values of the rate coefficients for RI, along with the experimental conditions, are listed in Table 1.

Hydroxyl radical sensitivity analysis was performed for the propene mixture at a representative temperature of $1101 \mathrm{~K}$ (Fig. 2). The $\mathrm{OH}$ sensitivity is calculated using the formula $S_{O H}=\left(\partial X_{O H} / \partial k_{i}\right) \times\left(k_{i} / X_{O H}\right)$, where $X_{O H}$ is the local OH-mole-fraction and $k_{i}$ is the rate constant of the $i^{\text {th }}$ reaction. The sensitivity plot shows that propene $+\mathrm{OH}$ is the dominant reaction at the chosen conditions. Secondary reactions such as $\mathrm{CH}_{3}+\mathrm{OH} \Leftrightarrow$ $\mathrm{CH}_{2}(\mathrm{~S})+\mathrm{H}_{2} \mathrm{O}(\mathrm{RVII}), \mathrm{CH}_{3}+\mathrm{CH}_{3}(+\mathrm{M}) \Leftrightarrow \mathrm{C}_{2} \mathrm{H}_{6}(+\mathrm{M})(\mathrm{RVIII})$, and $\mathrm{CH}_{3} \mathrm{COCH}_{3}+\mathrm{OH} \Leftrightarrow$ $\mathrm{H}_{2} \mathrm{O}+\mathrm{CH}_{2} \mathrm{CO}+\mathrm{CH}_{3}$ (RIX) were considered and they were found to have minor interference for $\mathrm{OH}$ time profiles. The rates for these important secondary reactions are updated based on the suggestions given in reference ${ }^{32}$ where the rate constant of RVII, RVIII, and RIX are updated from Pang et al. ${ }^{29}$, Oehlschlaeger et al. ${ }^{33}$, and Lam et al. ${ }^{34}$, respectively. 
Our measured rate constant data for RI are shown in Fig. 3 and compared with the measurements from Vasu et al. ${ }^{17}$, Smith et al. ${ }^{9}$, Bott and Cohen ${ }^{18}$, and Tully and Goldsmith ${ }^{13}$. Rate constants provided in the JetSurf 1.0 mechanism $^{31}$ and the theoretical study of Zador $e t$ $a l . .^{5}$ are also shown. As can be seen, our data agree very well with earlier measurements from Vasu et al. ${ }^{17}$ and Bott and Cohen ${ }^{18}$ with an average deviation of $11 \%$. Our values are slightly higher (about 20\%) than those of Vasu et al. ${ }^{17}$ at lower temperatures. This slight disagreement may be due to the reaction mechanism adopted by Vasu et al. ${ }^{17}$ in that the rate coefficients for secondary reactions were not updated. We note here that the secondary reactions play a more significant role at lower temperatures. We observed a marked positive temperature dependence for the propene $+\mathrm{OH}$ reaction over the temperature range of the current study. Comparing our $1 \mathrm{~atm}$ data with the $2-2.6 \mathrm{~atm}$ data of Vasu et al. ${ }^{17}$, no discernible pressure dependence is seen. This suggests that abstraction channels prevail over the addition channel at the high temperatures of the current work. At lower temperatures $(T \leq 600 \mathrm{~K})$, the addition channel is the dominant pathway that leads to various bimolecular products such as vinyl alcohol, allyl alcohol and propenols ${ }^{4-6}$. Our experimental data, including the ones from Vasu et $a l^{17}$., agree very well with the theoretical prediction of Zador et al. ${ }^{5}$ for the total abstraction rate coefficients with an average deviation of about $8 \%$ indicating that bimolecular addition channels at these temperatures are unimportant. Our calculations for the specific rate constants $k(E, J=0)$ were also found to be in line with these findings. The specific rate constants for the most dominant abstraction channel leading to allyl $+\mathrm{H} 2 \mathrm{O}$ were at least one order of magnitude higher than that of the major addition channel (vinyl alcohol $+\mathrm{CH} 3$ ) at all energies. This further suggests that $\mathrm{H}$ abstraction is the dominating pathway at the experimental conditions of the current study. The theoretical work by Zador et al. ${ }^{5}$ predicted the addition channel to be about $5 \%$ near $1000 \mathrm{~K}$. At the low temperatures $(\sim 900 \mathrm{~K})$ of the current study, the contribution of addition channels can increase slightly. The upper limit for 
the contribution of the addition channel in our measured rates has been estimated to be less than $9 \%$ which is within the reported uncertainties of our measured data. Therefore, our kinetic analyses described below assume that the addition channels for propene $+\mathrm{OH}$ reaction are of negligible importance in our temperature range. Theoretical studies ${ }^{4-6}$ have shown that the propene $+\mathrm{OH}$ reaction has three possible $\mathrm{H}$ abstraction channels:

$$
\begin{aligned}
& \mathrm{CH}_{2} \mathrm{CHCH}_{3}+\mathrm{OH} \stackrel{k_{3, \mathrm{H}}}{\longrightarrow} \mathrm{CH}_{2} \mathrm{CHCH}_{2}(\text { allyl })+\mathrm{H}_{2} \mathrm{O} \\
& \mathrm{CH}_{2} \mathrm{CHCH}_{3}+\mathrm{OH} \stackrel{k_{2, \mathrm{H}}}{\longrightarrow} \mathrm{CH}_{2} \mathrm{CCH}_{3}(\text { propen-2-yl })+\mathrm{H}_{2} \mathrm{O} \\
& \mathrm{CH}_{2} \mathrm{CHCH}_{3}+\mathrm{OH} \stackrel{k_{1, \mathrm{H}}}{\longrightarrow} \mathrm{CH}^{\circ} \mathrm{CHCH}_{3}(\text { propen-1-yl })+\mathrm{H}_{2} \mathrm{O}
\end{aligned}
$$

The branching ratios for RI are kept unchanged while fitting the experimentally measured $\mathrm{OH}$ profiles. The overall rate constant $\left(k_{\mathrm{I}}=k_{\mathrm{Ia}}+k_{\mathrm{Ib}}+k_{\mathrm{Ic}}\right)$ is insensitive to the branching ratios because of the pseudo-first-order conditions implemented here. The temperature dependence of the experimentally determined rate coefficients for the reaction RI is given by the following Arrhenius expression:

$$
k_{I}=1.07 \times 10^{-10} \exp (-2340 \mathrm{~K} / T) \mathrm{cm}^{3} \text { molecule }^{-1} \mathrm{~S}^{-1}(853-1442 \mathrm{~K})
$$

A detailed uncertainty analysis was performed to estimate the errors in the measured rate constant for RI at a representative condition of $1101 \mathrm{~K}$ and $1.38 \mathrm{~atm}$. Various sources of errors that were considered here include temperature $( \pm 0.7 \%)$, mixture composition $( \pm 5 \%)$, $\mathrm{OH}$ absorption coefficient $( \pm 3 \%)$, wavemeter reading $\left( \pm 0.002 \mathrm{~cm}^{-1}\right)$, errors in fitting the experimental profile $( \pm 5 \%)$, locating the time zero $( \pm 0.5 \mu \mathrm{s})$, and rate constants of the secondary reactions. The contribution of each of these error sources on the determination of $k_{\mathrm{I}}$ 
is calculated separately. The overall uncertainty is calculated using the root-sum-squared method and is found to be $\pm 17 \%$ for $k_{\mathrm{I}}$ at $1101 \mathrm{~K}$.

The rate coefficients for the reaction of $\mathrm{OH}$ with other five propene isotopes were determined in a manner analogous to the one described for propene $+\mathrm{OH}$. Fuel concentrations of $302-312$ ppm were used for propene-1-d1, propene-1,1-d2, propene-112D3, propene-3,3,3-d3, and propene-d6. The partial pressure of TBHP $(10-20 \mathrm{ppm})$ was chosen in such a way that the reaction of deuterated propene $+\mathrm{OH}$ obeys the pseudo-firstorder kinetics. Uncertainties for $k_{\mathrm{II}}, k_{\mathrm{III}} k_{\mathrm{IV}}, k_{\mathrm{V}}$, and $k_{\mathrm{VI}}$ were estimated to be $\pm 18 \%$ at $1039 \mathrm{~K}$, $\pm 16 \%$ at $1145 \mathrm{~K}, \pm 17 \%$ at $1104 \mathrm{~K}, \pm 17 \%$ at $1108 \mathrm{~K}$, and $\pm 18 \%$ at $1054 \mathrm{~K}$, respectively. Arrhenius plots for reactions RII - RVI are shown in Fig. 4 and the measured rate constants are listed in Tables $2-6$. The best fits to our experimental data yield the following Arrhenius expressions:

$$
\begin{aligned}
& k_{I I}=1.03 \times 10^{-10} \exp (-2321 \mathrm{~K} / T) \mathrm{cm}^{3} \text { molecule }^{-1} \mathrm{~s}^{-1}(818-1366 \mathrm{~K}) \\
& k_{I I I}=1.15 \times 10^{-10} \exp (-2486 \mathrm{~K} / T) \mathrm{cm}^{3} \text { molecule }^{-1} \mathrm{~s}^{-1}(881-1379 \mathrm{~K}) \\
& k_{I V}=1.14 \times 10^{-10} \exp (-2492 \mathrm{~K} / \mathrm{T}) \mathrm{cm}^{3} \text { molecule }^{-1} \mathrm{~s}^{-1}(832-1369 \mathrm{~K}) \\
& k_{V}=9.50 \times 10^{-11} \exp (-2390 \mathrm{~K} / T) \mathrm{cm}^{3} \text { molecule }^{-1} \mathrm{~s}^{-1}(904-1460 \mathrm{~K}) \\
& k_{V I}=10.3 \times 10^{-11} \exp (-2540 \mathrm{~K} / \mathrm{T}) \mathrm{cm}^{3} \text { molecule }^{-1} \mathrm{~s}^{-1}(888-1340 \mathrm{~K})
\end{aligned}
$$

As allylic H-atom abstraction is both kinetically and thermodynamically favored ${ }^{4,5}$, the $\mathrm{OH}$ radical attack occurs preferentially at the allylic site $\left(-\mathrm{CH}_{3}\right)$ of propene. One would expect that the abstraction rate will be smaller for $\mathrm{D}$ atom as compared to that of an $\mathrm{H}$ atom. The effect of deutration on abstraction from the allylic site is best seen in Fig. 4 by comparing the rate coefficients for reaction $\mathrm{R}_{\mathrm{I}}$ with $\mathrm{R}_{\mathrm{V}}$ and $\mathrm{R}_{\mathrm{VI}}$. 


\subsection{Site-Specific Rate Constants and Branching Ratios}

Many researchers, including Tully and co-workers ${ }^{13,35,36}$, have analyzed their kinetic data for alkane $+\mathrm{OH}$ reactions by summing up the primary, secondary, and tertiary site-specific rate constants as follows:

$$
k_{O H+\text { alkane }}=n_{p} * k_{p}+n_{s} * k_{s}+n_{t} * k_{t}
$$

Where $n_{\mathrm{p}}, n_{\mathrm{s}}$, and $n_{\mathrm{t}}$, are the number of primary, secondary, and tertiary hydrogen atoms in alkane; $k_{\mathrm{p}}, k_{\mathrm{s}}$, and $k_{\mathrm{t}}$ are the corresponding primary, secondary, and tertiary site-specific rate constants per $\mathrm{H}$-atom. The experimentally observed overall rate constants for alkenes $+\mathrm{OH}$ can also be expressed in a similar way by considering all types of $\mathrm{H}$ atoms present in the molecule. Cohen ${ }^{37,} 38$ used the group-additivity transition-state-theory (TST) method to reproduce the measurements of the rate constants of $\mathrm{OH}$ with a series of alkanes. The proposed method was based on defining $\mathrm{C}-\mathrm{H}$ bonds in alkanes according to the number of carbon atoms bonded to the next-nearest-neighbor (NNN) carbon. Recently, Sivaramakrishnan et al. ${ }^{39,40}$ and Badra et al. ${ }^{26,28,32}$ extended these estimation methods to determine three-parameter-fits for several site-specific $\mathrm{H}$-abstraction rate constants. Their derived rates reproduced the experimental $\mathrm{OH}+$ alkane rate constants for a variety of normal and branched alkanes. However, we note here that their site-specific rate constant expressions cannot be employed to calculate the total rate constants for $\mathrm{OH}+$ unsaturated molecules, such as alkenes, due to the presence of the double bond and its effect on the $\mathrm{C}-\mathrm{H}$ bond enthalpy at various sites. In the propene molecular chain, two types of C-H bonds are present, namely vinylic $\left(-\mathrm{CH}_{2}\right.$ and $\left.-\mathrm{CH}\right)$ and allylic $\left(-\mathrm{CH}_{3}\right)$. As $-\mathrm{CH}_{2}$ and $-\mathrm{CH}$ vinylic $\mathrm{H}$-atoms in propene were found to exhibit their kinetics differently ${ }^{4-6}$, these H-atoms are treated separately in our work. A system of six equations and six unknowns can be obtained by employing Eq. (7) to 
the reaction of $\mathrm{OH}$ with six deuterated propenes. Therefore, $k_{\mathrm{I}}-k_{\mathrm{VI}}$ can be expressed as follows:

$$
\begin{aligned}
& k_{I}=3 k_{3, H}+2 k_{1, H}+k_{2, H} \\
& k_{I I}=3 k_{3, H}+k_{1, H}+k_{1, D}+k_{2, H} \\
& k_{I I I}=3 k_{3, H}+2 k_{1, D}+k_{2, H} \\
& k_{I V}=3 k_{3, H}+2 k_{1, D}+k_{2, D} \\
& k_{V}=3 k_{3, D}+2 k_{1, H}+k_{2, H} \\
& k_{V I}=3 k_{3, D}+2 k_{1, D}+k_{2, D}
\end{aligned}
$$

Here, $k_{1}, k_{2}$ and $k_{3}$ are the abstraction rate coefficient per $\mathrm{H}$ (or D) atom at the first, second and third carbon atom, respectively; carbon atom numbering is based on IUPAC nomenclature of alkenes. This set of six equations have six unknowns $k_{3, \mathrm{H}}, k_{3, \mathrm{D}}, k_{1, \mathrm{H}}, k_{1, \mathrm{D}}, k_{2, \mathrm{H}}$, and $k_{2, \mathrm{D}}$. However, only four independent equations are obtained even if more possible propene isotopes are considered. This is because, for the system of linear equations given above, two possible equalities can be derived:

$$
\begin{aligned}
k_{I I}= & 0.5\left(k_{I I I}+k_{I}\right) \\
& k_{V I}+k_{V}=k_{I V}+k_{I}
\end{aligned}
$$

Equations (14) and (15) must hold for all temperatures. The experimental results show that the above equalities are valid with an average deviation of $2.5 \%$ for Eq. (14) and $4 \%$ for Eq. (15) for the entire $T$-range of our study; see Table 7 . The rate constant values presented in Table 7 are obtained from the Arrhenius fittings of our experimental data. Hence, the system of six equations can be reduced to a system of four independent equations and two more 
equations or assumptions are needed to fully determine the six unknown site-specific rate constants.

Tully et al. ${ }^{36}$ measured the rate constants for $\mathrm{H}$ and $\mathrm{D}$ abstraction by $\mathrm{OH}$ from ethene isotopes $\left(\mathrm{C}_{2} \mathrm{H}_{4}\right.$ and $\left.\mathrm{C}_{2} \mathrm{D}_{4}\right)$ where all four vinylic $\mathrm{H}$ or $\mathrm{D}$ atoms are equivalent. From the Tully et $a l .{ }^{36}$ work, we derived an expression for the ratio of $\mathrm{H}$ and $\mathrm{D}$ abstraction of vinylic atoms:

$$
\frac{k_{1, H}}{k_{1, D}}=0.52 \times \exp \left(\frac{1022}{T}\right)
$$

For both ethene and propene, the vinylic C-H bond strength is about $110.9 \mathrm{kcal} / \mathrm{mole}^{41,42}$, therefore, it is valid to apply Eq. (16) to the propene system. A similar approach of applying the ratio of primary $\mathrm{H}$ and $\mathrm{D}$ abstraction in propane to allylic $\mathrm{H} / \mathrm{D}$ abstraction in propene cannot be justified. The bond enthalpy for allylic C-H bond of propene is far too low $\left(88.8^{41}\right.$, $\left.88.2^{42} \mathrm{kcal} / \mathrm{mole}\right)$ compared to the primary $\mathrm{C}-\mathrm{H}$ bond $(100.9 \mathrm{kcal} / \mathrm{mole})^{42}$ of propane. The consequence of this difference in bond enthalpies is that the ratio of primary $\left(-\mathrm{CH}_{3}\right) \mathrm{H}$ and D abstraction rate $\left(k_{\mathrm{H}} / k_{\mathrm{D}}\right)$ for propane exhibits a much stronger temperature dependence than it does for the allylic ratio $\left(k_{\mathrm{H}} / k_{\mathrm{D}}\right)$ of propene. For this reason, we deduced a ratio $\left(k_{3, \mathrm{H}} / k_{3, \mathrm{D}}\right)$ for allylic $\mathrm{H}$ - and D- abstraction from propene using the following equation:

$\frac{k_{3, H}}{k_{3, D}}(T)=\left[\frac{k_{I}(T)-k_{2, H}(T)-2 k_{1, H}(T)}{k_{V}(T)-k_{2, H}(T)-2 k_{1, H}(T)}\right]$

Here, $k_{2, \mathrm{H}}$ and $k_{1, \mathrm{H}}$ (vinylic $\mathrm{H}$-abstraction rates of propene $+\mathrm{OH}$ reaction) are taken from Zador et al. ${ }^{5} ; k_{\mathrm{I}}$ and $k_{\mathrm{V}}$ are our measured rate constants for reactions (1) and (5), respectively. Our computed ratio for allylic $\mathrm{H}$ - and $\mathrm{D}$ - abstraction $\left(k_{3, \mathrm{H}} / k_{3, \mathrm{D}}\right)$ of propene by $\mathrm{OH}$ radicals can be given by:

$$
\frac{k_{3, H}}{k_{3, D}}(T)=3.5 \times 10^{-3} \times T^{0.76} \times \exp \left(\frac{585}{T}\right)
$$

These two additional equations (Eq. (16) and Eq. (18)) can be used with any four of the measured rate constant expressions (Eq. (8) - (13)) to determine the desired site-specific 
rate constants. One can use several combinations of four isotopes to perform the calculations. A more rigorous analysis which utilizes all available measured rate constant data and takes into account the uncertainty of all experimental rates should be considered. Therefore, the six measured reaction rate constant expressions $k_{\mathrm{I}}, k_{\mathrm{II}}, k_{\mathrm{III}}, k_{\mathrm{IV}}, k_{\mathrm{V}}$, and $k_{\mathrm{VI}}$ combined with the two additional H/D ratio equations are used in an optimization algorithm to calculate the optimal set of site-specific rates. A least square error analysis is adopted where the objective function is:

$$
f(\underline{X})=\sum_{i=1}^{i=6}\left(k_{i}^{e x p}-k_{i}^{S}(\underline{X})\right)^{2}
$$

Here, $k_{i}^{\text {exp }}$ is the experimentally measured overall rate constant of the ith isotope at temperature $T, k_{i}^{S}$ is the overall rate constant calculated from the determined site-specific rates and $\underline{\boldsymbol{X}}$ is the vector of site-specific rates for $\mathrm{H}$ and $\mathrm{D}$ abstractions at temperature T. This objective function can be written in matrix notation as:

$$
f(\underline{X})=(\underline{k}-\underline{A X})^{T}(\underline{k}-\underline{A X})
$$

where $\underline{\underline{\boldsymbol{A}}}$ is the representative matrix containing the coefficients of the right hand side of Eqs. (8) - Eq. (13) and $\mathbf{k}$ is the representative vector of the left hand side of Eqs. (8) - (13). The gradient of this function is then

$$
\nabla_{X} f(\underline{X})=2 \underline{A}^{T} \underline{\underline{A X}}-2 \underline{A}^{T} \underline{k}
$$

The method of descent gradient could be used to find the optimal value of $\boldsymbol{X}$ that minimizes the objective function $f(\underline{X})$ at each temperature. Theoretically, this method should converge to a unique optimal solution $X_{o p t}$ since we have a linear system of six independent equations and six unknowns. However, the experimental uncertainty introduces a correction term in each equation which makes the optimization problem much more complex and eventually local solutions could appear. To avoid this problem, one has to take into consideration the 
overall error distribution as well as the domain of feasible solutions. A similar treatment was adopted by Tully and coworkers ${ }^{35,36,44-47}$ who used a non-linear least square parameter fitting routine to minimize the sum of the squares of the residuals, defined in Eq. (19), weighted by the associated uncertainty of each rate constant. With the application of this optimization routine, the maximum error is evaluated to be less than $3 \%$ for all isotopes which is much less than the experimental uncertainty; see Fig. 5. It should be noted that the final results (sitespecific rate constants, branching ratios) are not very sensitive to the two additional input equations, Eqs. (16) and (18). This is because the optimization scheme minimizes the error in the prediction of measured rate constants (reactions RI to RVI) by the derived site-specific rate constants.

Following the methodology described above, a unique solution for site-specific rate constants is obtained; the results are plotted in Fig. 6. The Arrhenius expressions for the derived site-specific rate constants are given below:

$$
\begin{aligned}
& k_{3, \mathrm{H}}=2.32 \times 10^{-11} \exp (-2341 \mathrm{~K} / T) \mathrm{cm}^{3} \text { molecule }^{-1} \mathrm{~s}^{-1} \\
& k_{3, \mathrm{D}}=1.96 \times 10^{-11} \exp (-2420 \mathrm{~K} / T) \mathrm{cm}^{3} \text { molecule }^{-1} \mathrm{~s}^{-1} \\
& k_{1, \mathrm{H}}=1.39 \times 10^{-11} \exp (-2270 \mathrm{~K} / T) \mathrm{cm}^{3} \text { molecule }^{-1} \mathrm{~s}^{-1} \\
& k_{1, \mathrm{D}}=1.95 \times 10^{-11} \exp (-2868 \mathrm{~K} / \mathrm{T}) \mathrm{cm}^{3} \text { molecule }^{-1} \mathrm{~s}^{-1} \\
& k_{2, \mathrm{H}}=7.2 \times 10^{-12} \exp (-2282 \mathrm{~K} / T) \mathrm{cm}^{3} \text { molecule }^{-1} \mathrm{~s}^{-1} \\
& k_{2, \mathrm{D}}=7.69 \times 10^{-12} \exp (-2575 \mathrm{~K} / T) \mathrm{cm}^{3} \text { molecule }^{-1} \mathrm{~s}^{-1}
\end{aligned}
$$

It is discernible from Fig. 6 that the site-specific abstraction rate for allylic site is measured to be larger than that of the vinylic sites. As expected, our results show that the Dabstraction rate is smaller than the $\mathrm{H}$-abstraction rate for a given channel. In addition, these 
results also indicated that the deutration at the vinylic sites $\left(=\mathrm{CH}_{2}\right.$ or $\left.=\mathrm{CH}\right)$ exhibits stronger temperature dependence as compared to the deutration at the allylic site $\left(-\mathrm{CH}_{3}\right)$. As stated earlier, this behaviour is primarily due to the difference in their bond enthalpies viz. 111 $\mathrm{kcal} / \mathrm{mol}$ for vinylic $\mathrm{C}-\mathrm{H}$ bond and $88.8 \mathrm{kcal} / \mathrm{mol}$ for allylic $\mathrm{C}-\mathrm{H}$ bond ${ }^{42}$. The observed trends will lead to the crossover of the vinylic $\mathrm{H}$ - and D- abstraction rates at higher temperatures which is in line with Tully et al. ${ }^{47}$ experiments.

The total rate coefficients for the abstraction channels leading to allyl (RIa), propen-2yl (RIb) and propen-1-yl (RIc) can be deduced from the site-specific rate constants; these are presented in Fig. 7. As can be seen, the allyl-producing channel is the most dominant followed by propen-1-yl channel.

As mentioned earlier, few research groups ${ }^{4-6}$ computed rate coefficients for the sitespecific $\mathrm{H}$ abstraction of propene by $\mathrm{OH}$ radicals. In Fig. 8, our measured site-specific rate constants for the three abstraction channels are compared with theoretical predictions. As can be seen, there are large discrepancies in the calculated rate coefficients for the site-specific $\mathrm{H}$ abstraction. The theoretical predictions of Zhou et $a l .{ }^{4}$ are significantly lower compared to other theoretical studies and our experimental results. As pointed out by Zádor et al. ${ }^{5}$, the under-prediction of $k_{3, \mathrm{H}}$ by Zhou et al. $^{4}$ may have been caused by not taking hindered internal rotor into consideration, whereas the discrepancy for $k_{1, \mathrm{H}}$ and $k_{2, \mathrm{H}}$ could be due to the differences in the barrier heights of the corresponding abstraction channels. Our values for the allylic $\mathrm{H}$-abstraction $\left(k_{3, \mathrm{H}}\right)$ agree well with Zádor et al. ${ }^{5}$ and Tsang ${ }^{25}$ with minor discrepancies at temperatures above $1100 \mathrm{~K}$. Our measurements revealed that the total abstraction rate for propen-1-yl channel is more favorable than the propen-2-yl (see Fig. 7), which is in line with the theoretical prediction of Zádor et $a l^{5}$. However, our site-specific rates for $k_{1, \mathrm{H}}$ are measured to be larger than $k_{2, \mathrm{H}}$, whereas Zádor et $\mathrm{al}^{5}$ and Tsang ${ }^{25}$ predict that $k_{2, \mathrm{H}}$ to be larger. 
Branching ratios for the different $\mathrm{H}$ abstraction channels are calculated and compared with previous theoretical studies in Fig. 9 and Table 9. As can be seen, all studies predict that allyl-producing channel is dominant over the entire $T$-range of our study. However, our branching ratio for this channel is lower than that of Zádor et al. ${ }^{5}$ and $\mathrm{Tsang}^{25}$. Our experimentally determined branching ratio for this channel remains almost unchanged at about $65 \%$ as opposed to that of Zádor et al. $^{5}$ and Tsang $^{25}$ who predicted a slight decrease with increasing temperature. At $1400 \mathrm{~K}$, their predicted values, $74 \%$ for Zádor et $a .^{5}$ and $70 \%$ for $\mathrm{Tsang}^{25}$, are quite close to our experimental value. Interestingly, Zhou et al. ${ }^{4}$ branching ratio for the allyl channel comes out to be in good agreement with the measured value. The branching ratios for the propen-1-yl and propen-2-yl production channels show larger deviations. In our work, propen-1-yl channel is found to have the second highest branching ratio of about $28 \%$, whereas Zádor et al. ${ }^{5}$ and Tsang ${ }^{25}$ predict about $10 \%$ for this channel and Zhou et al. ${ }^{4}$ predict about 5\%. For propene-2-yl channel, our measurements agree with the theoretical studies of Zádor et al. ${ }^{5}$ and $\mathrm{Tsang}^{25}$ within $5 \%$, whereas Zhou et al. ${ }^{4}$ reported a branching ratio of $30 \%$ which significantly over-predicts our measurements. The reasons for these discrepancies have been discussed earlier. In general, our branching ratios for the three channels showed no or little temperature dependence over the temperature range of our study.

\subsection{Extension to Butene + OH}

Using the same methodology for defining the rate constants of alkenes $+\mathrm{OH}$ as summations of site-specific $\mathrm{H}$ abstraction rate constants, one can derive expressions for site specific rate coefficient for $\mathrm{H}$ atom abstraction of higher alkenes. Vasu et al. ${ }^{48}$ measured the rate constants of butene isomers (1-butene, trans-2-butene, and cis-2-butene) with $\mathrm{OH}$ using shock tube/laser absorption techniques at high temperatures. The measured rate constant 
values (in $\mathrm{cm}^{3}$ molecule $\mathrm{s}^{-1}$ ) of Vasu et al. ${ }^{48}$ are written as summation of site-specific rate constants as follows:

$$
k_{1-\text { butene }+O H}=3 k_{4}+2 k_{1}+k_{2, \text { trans }}+2 k_{3}=2.06 \times 10^{-10} \exp (-2295 \mathrm{~K} / T)(880-1341 \mathrm{~K})
$$

$$
\begin{gathered}
k_{\text {trans-2-butene }+O H}=6 k_{1}+2 k_{2, \text { trans }}=4.0 \times 10^{-10} \exp (-3026 \mathrm{~K} / \mathrm{T})(1024-1339 \mathrm{~K}) \\
k_{\text {cis-2-butene }+O H}=6 k_{1}+2 k_{2, \text { cis }}=2.44 \times 10^{-10} \exp (-2613 \mathrm{~K} / \mathrm{T})(1169-1296 \mathrm{~K})
\end{gathered}
$$

The subscript in the rate coefficient identifies the position of the hydrogen atom according to IUPAC nomenclature of alkenes. Here, $k_{4}$ is the primary $\mathrm{H}$ abstraction which is same as in $\mathrm{n}$ butane, and $k_{1}$ is the vinylic $\mathrm{H}$ abstraction which is taken equal to the RIc channel of propene $+\mathrm{OH}$ reaction. The value of $k_{4}$ is taken from Sivaramakrishnan and Michael $^{40}$ who investigated the reactions of various alkanes with $\mathrm{OH}$ radical. The $k_{2, \text { trans }}$ is assumed to be same in 1-butene and trans-2-butene. The three equations given above, Eqs. (28) - (30), have

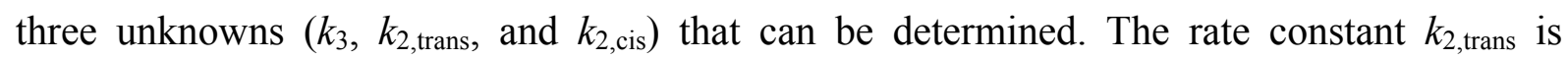
calculated from Eq. (29) and it has the following Arrhenius expression:

$$
k_{2, \text { trans }}=2.27 \times 10^{-10} \exp (-4350 \mathrm{~K} / T) \mathrm{cm}^{3} \text { molecule }{ }^{-1} \mathrm{~s}^{-1}(1024-1339 \mathrm{~K})
$$

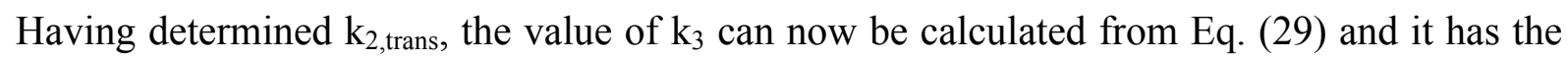
following Arrhenius expression:

$$
k_{3}=2.47 \times 10^{-11} \exp (-1534 \mathrm{~K} / T) \mathrm{cm}^{3} \text { molecule } \mathrm{s}^{-1}(1024-1339 \mathrm{~K})
$$

Similarly, $k_{2, \text { cis }}$ can be calculated from Eq. (30) and its Arrhenius expression is:

$$
k_{2, \mathrm{cis}}=6.29 \times 10^{-11} \exp (-3334 \mathrm{~K} / T) \mathrm{cm}^{3} \text { molecule }^{-1} \mathrm{~s}^{-1}(1169-1296 \mathrm{~K})
$$

The Arrhenius parameters for the determined site-specific rate constants for $\mathrm{H}$ and $\mathrm{D}$ abstractions of alkenes by $\mathrm{OH}$ are summarized in Table 8 . Unfortunately, high-temperature 
rate data are not available for other alkenes $+\mathrm{OH}$ to validate the derived site-specific $\mathrm{H}$ abstraction rate constants. Hence, high-temperature measurements for well-chosen alkenes + $\mathrm{OH}$ reactions are needed.

\section{Conclusions}

The measurements for the rate coefficients of several propene isotopes $+\mathrm{OH}$ were carried out behind reflected shock waves. Six deuterated propene isotopes were employed to extract sitespecific $\mathrm{H}$ abstraction rate coefficients over a temperature range of $818-1460 \mathrm{~K}$. The addition channels are found to be negligible over the studied temperature range. Among the abstraction channels, allyl channel was found to be the most dominant abstraction channel followed by propen-1-yl and propen-2-yl channels. These findings are in line with previous theoretical studies, however, discrepancies existed in the magnitude of the site-specific rate coefficients. New site-specific rate constants are also derived for $\mathrm{H}$ abstraction by $\mathrm{OH}$ from higher alkenes (1-butene, trans-2-butene, and cis-2-butene). The derived site-specific rate constants will prove very useful in the calculation of branching ratios for $\mathrm{OH}+$ alkene reactions.

\section{Acknowledgements}

We would like to acknowledge the funding support from Saudi Aramco under the FUELCOM program and by King Abdullah University of Science and Technology (KAUST). 


\section{References}

1. K. J. Morganti, M. F. Tien, M. J. Brear, G. Da Silva, Y. Yi, F. L. Dryer, The Research and Motor octane numbers of Liquefied Petroleum Gas (LPG), Elsevier, Kidlington, ROYAUME-UNI, 2013.

2. C. A. Taatjes, N. Hansen, A. McIlroy, J. A. Miller, J. P. Senosiain, S. J. Klippenstein, F. Qi, L. Sheng, Y. Zhang, T. A. Cool, J. Wang, P. R. Westmoreland, M. E. Law, T. Kasper and K. Kohse-Höinghaus, Science, 2005, 308, 1887-1889.

3. C. A. Taatjes, N. Hansen, J. A. Miller, T. A. Cool, J. Wang, P. R. Westmoreland, M. E. Law, T. Kasper and K. Kohse-Höinghaus, The Journal of Physical Chemistry A, 2005, 110, 3254-3260.

4. C.-W. Zhou, Z.-R. Li and X.-Y. Li, The Journal of Physical Chemistry A, 2009, 113, 2372-2382.

5. J. Zador, A. W. Jasper and J. A. Miller, Physical Chemistry Chemical Physics, 2009, 11, 11040-11053.

6. L. K. Huynh, H. R. Zhang, S. Zhang, E. Eddings, A. Sarofim, M. E. Law, P. R. Westmoreland and T. N. Truong, The Journal of Physical Chemistry A, 2009, 113, $3177-3185$.

7. C. K. Westbrook, W. J. Pitz and H. J. Curran, The Journal of Physical Chemistry A, 2006, 110, 6912-6922.

8. R. Atkinson and J. N. Pitts, The Journal of Chemical Physics, 1975, 63, 3591-3595.

9. G. P. Smith, P. W. Fairchild, J. B. Jeffries and D. R. Crosley, The Journal of Physical Chemistry, 1985, 89, 1269-1278.

10. T. Spangenberg, S. Köhler, B. Hansmann, U. Wachsmuth, B. Abel and M. A. Smith, The Journal of Physical Chemistry A, 2004, 108, 7527-7534. 
11. T. Klein, I. Barnes, K. H. Becker, E. H. Fink and F. Zabel, The Journal of Physical Chemistry, 1984, 88, 5020-5025.

12. A. B. Vakhtin, J. E. Murphy and S. R. Leone, The Journal of Physical Chemistry A, 2003, 107, 10055-10062.

13. F. P. Tully and J. E. M. Goldsmith, Chemical Physics Letters, 1985, 116, 345-352.

14. A. V. Pastrana and R. W. Carr Jr, The Journal of Physical Chemistry, 1975, 79, 765770.

15. R. Zellner and K. Lorenz, The Journal of Physical Chemistry, 1984, 88, 984-989.

16. C. Kappler, J. Zádor, O. Welz, X. Fernandez Ravi, M. Olzmann and A. Taatjes Craig, in Zeitschrift für Physikalische Chemie International journal of research in physical chemistry and chemical physics, 2011, vol. 225, p. 1271.

17. S. S. Vasu, Z. Hong, D. F. Davidson, R. K. Hanson and D. M. Golden, The Journal of Physical Chemistry A, 2010, 114, 11529-11537.

18. J. F. Bott and N. Cohen, International Journal of Chemical Kinetics, 1991, 23, 10751094.

19. R. A. Yetter and F. L. Dryer, Symposium (International) on Combustion, 1992, 24, $757-767$.

20. I. Díaz-Acosta, J. R. Alvarez-Idaboy and A. Vivier-Bunge, International Journal of Chemical Kinetics, 1999, 31, 29-36.

21. J. R. Alvarez-Idaboy, I. Díaz-Acosta and A. Vivier-Bunge, Journal of Computational Chemistry, 1998, 19, 811-819.

22. M. Szőri, C. Fittschen, I. G. Csizmadia and B. Viskolcz, Journal of Chemical Theory and Computation, 2006, 2, 1575-1586.

23. A. M. El-Nahas, T. Uchimaru, M. Sugie, K. Tokuhashi and A. Sekiya, Journal of Molecular Structure: THEOCHEM, 2006, 770, 59-65. 
24. R. Izsák, M. Szőri, P. J. Knowles and B. Viskolcz, Journal of Chemical Theory and Computation, 2009, 5, 2313-2321.

25. W. Tsang, Journal of Physical and Chemical Reference Data, 1991, 20, 221-273.

26. J. Badra, A. Elwardany and A. Farooq, Proceedings of the Combustion Institute, 2014.

27. J. Badra, A. E. Elwardany and A. Farooq, Physical Chemistry Chemical Physics, 2014, 16, 12183-12193.

28. J. Badra, E. F. Nasir and A. Farooq, The Journal of Physical Chemistry A, 2014, 118, 4652-4660.

29. G. A. Pang, R. K. Hanson, D. M. Golden and C. T. Bowman, Zeitschrift für Physikalische Chemie, 2011, 225, 1157-1178.

30. V. Vasudevan, D. F. Davidson and R. K. Hanson, Journal of Physical Chemistry A, 2005, 109, 3352-3359.

31. B. Sirjean, E. Dames, D. Sheen, X. You, C. Sung, A. Holley, F. Egolfopoulos, H. Wang, S. Vasu and D. Davidson, JetSurF version, 2008, 1.

32. J. Badra, A. E. Elwardany, F. Khaled, S. S. Vasu and A. Farooq, Combustion and Flame, 2014, 161, 725-734.

33. M. A. Oehlschlaeger, D. F. Davidson and R. K. Hanson, Proceedings of the Combustion Institute, 2005, 30, 1119-1127.

34. K. Lam, D. Davidson and R. Hanson, Journal of Physical Chemistry A, 2012, 116, 5549-5559.

35. A. T. Droege and F. P. Tully, The Journal of Physical Chemistry, 1986, 90, 59375941.

36. F. P. Tully, Chemical physics letters, 1988, 143, 510-514.

37. N. Cohen, International Journal of Chemical Kinetics, 1982, 14, 1339-1362.

38. N. Cohen, International Journal of Chemical Kinetics, 1991, 23, 397-417. 
39. R. Sivaramakrishnan and J. V. Michael, Journal of Physical Chemistry A, 2009, 113, $5047-5060$.

40. R. Sivaramakrishnan, N. K. Srinivasan, M. C. Su and J. V. Michael, Proceedings of the Combustion Institute, 2009, 32, 107-114.

41. S. J. Blanksby and G. B. Ellison, Accounts of Chemical Research, 2003, 36, 255-263.

42. Y. R. Luo, in Comprehensive Handbook of Chemical Bond Energies, CRC Press, 2007, pp. 19-145.

43. L. Vereecken and J. Peeters, Chemical Physics Letters, 2001, 333, 162-168.

44. A. T. Droege and F. P. Tully, The Journal of Physical Chemistry, 1986, 90, 19491954.

45. A. T. Droege and F. P. Tully, Journal of Physical Chemistry, 1987, 91, 1222-1225.

46. F. P. Tully, A. T. Droege, M. Koszykowski and C. F. Melius, The Journal of Physical Chemistry, 1986, 90, 691-698.

47. F. P. Tully, M. L. Koszykowski and J. Stephen Binkley, Symposium (International) on Combustion, 1985, 20, 715-721.

48. S. S. Vasu, L. K. Huynh, D. F. Davidson, R. K. Hanson and D. M. Golden, The Journal of Physical Chemistry A, 2011, 115, 2549-2556. 
Table 1. High-temperature rate constant data for propene $+\mathrm{OH}=>$ Products.

\begin{tabular}{ccc}
\hline$T_{5}(\mathrm{~K})$ & $P_{5}(\mathrm{~atm})$ & $k_{\mathrm{I}}\left(\mathrm{cm}^{3}\right.$ molecule $\left.^{-1} \mathrm{~s}^{-1}\right)$ \\
\hline 853 & 1.30 & $7.20 \times 10^{-12}$ \\
893 & 1.42 & $7.91 \times 10^{-12}$ \\
911 & 1.31 & $8.24 \times 10^{-12}$ \\
974 & 1.29 & $9.52 \times 10^{-12}$ \\
1082 & 1.57 & $1.19 \times 10^{-11}$ \\
1101 & 1.37 & $1.24 \times 10^{-11}$ \\
1212 & 1.35 & $1.52 \times 10^{-11}$ \\
1442 & 1.43 & $2.21 \times 10^{-11}$
\end{tabular}


Table 2. High-temperature rate constant data for propene-1-d1 $+\mathrm{OH}=>$ Products.

\begin{tabular}{ccc}
\hline$T_{5}(\mathrm{~K})$ & $P_{5}(\mathrm{~atm})$ & $k_{\mathrm{II}}\left(\mathrm{cm}^{3}\right.$ molecule $\left.^{-1} \mathrm{~s}^{-1}\right)$ \\
\hline 818 & 1.34 & $6.40 \times 10^{-12}$ \\
882 & 1.39 & $7.70 \times 10^{-12}$ \\
970 & 1.29 & $9.37 \times 10^{-12}$ \\
1039 & 1.24 & $1.07 \times 10^{-11}$ \\
1171 & 1.27 & $1.38 \times 10^{-11}$ \\
1268 & 1.18 & $1.63 \times 10^{-11}$ \\
1334 & 1.14 & $1.82 \times 10^{-11}$ \\
1366 & 1.15 & $1.92 \times 10^{-11}$
\end{tabular}


Table 3. High-temperature rate constant data for propene-1,1-d2 $+\mathrm{OH}=>$ Products.

\begin{tabular}{ccc}
\hline$T_{5}(\mathrm{~K})$ & $P_{5}(\mathrm{~atm})$ & $k_{\mathrm{III}}\left(\mathrm{cm}^{3} \mathrm{molecule}^{-1} \mathrm{~s}^{-1}\right)$ \\
\hline 881 & 1.10 & $7.00 \times 10^{-12}$ \\
951 & 1.42 & $8.63 \times 10^{-12}$ \\
999 & 1.83 & $9.57 \times 10^{-12}$ \\
1062 & 1.30 & $1.09 \times 10^{-11}$ \\
1070 & 2.07 & $1.11 \times 10^{-11}$ \\
1104 & 1.15 & $1.18 \times 10^{-11}$ \\
1182 & 1.03 & $1.39 \times 10^{-11}$ \\
1315 & 1.10 & $1.72 \times 10^{-11}$ \\
1379 & 1.22 & $1.91 \times 10^{-11}$
\end{tabular}


Table 4. High-temperature rate constant data for propene-1,1,2-d3 $+\mathrm{OH}=>$ Products.

\begin{tabular}{ccc}
\hline$T_{5}(\mathrm{~K})$ & $P_{5}(\mathrm{~atm})$ & $k_{\mathrm{IV}}\left(\mathrm{cm}^{3} \mathrm{molecule}^{-1} \mathrm{~s}^{-1}\right)$ \\
\hline 896 & 1.58 & $7.54 \times 10^{-12}$ \\
910 & 1.47 & $7.60 \times 10^{-12}$ \\
989 & 1.34 & $9.29 \times 10^{-12}$ \\
1058 & 1.28 & $1.05 \times 10^{-11}$ \\
1146 & 1.96 & $1.27 \times 10^{-11}$ \\
1149 & 1.23 & $1.28 \times 10^{-11}$ \\
1159 & 1.37 & $1.30 \times 10^{-11}$ \\
1298 & 1.30 & $1.60 \times 10^{-11}$ \\
1437 & 1.25 & $2.07 \times 10^{-11}$
\end{tabular}


Table 5. High-temperature rate constant data for propene-3,3,3-d3 $+\mathrm{OH}=>$ Products.

\begin{tabular}{ccc}
\hline$T_{5}(\mathrm{~K})$ & $P_{5}(\mathrm{~atm})$ & $k_{\mathrm{V}}\left(\mathrm{cm}^{3}\right.$ molecule $\left.^{-1} \mathrm{~s}^{-1}\right)$ \\
\hline 904 & 1.45 & $6.87 \times 10^{-12}$ \\
907 & 1.62 & $7.00 \times 10^{-12}$ \\
972 & 1.48 & $8.02 \times 10^{-12}$ \\
1024 & 1.41 & $8.95 \times 10^{-12}$ \\
1108 & 1.40 & $1.05 \times 10^{-11}$ \\
1185 & 1.30 & $1.28 \times 10^{-11}$ \\
1246 & 1.16 & $1.36 \times 10^{-11}$ \\
1325 & 1.16 & $1.55 \times 10^{-11}$ \\
1460 & 1.32 & $2.00 \times 10^{-11}$
\end{tabular}


Table 6. High-temperature rate constant data for propene-d6 $+\mathrm{OH}=>$ Products.

\begin{tabular}{ccc}
\hline$T_{5}(\mathrm{~K})$ & $P_{5}(\mathrm{~atm})$ & $k_{\mathrm{VI}}\left(\mathrm{cm}^{3} \mathrm{molecule}^{-1} \mathrm{~s}^{-1}\right)$ \\
\hline 888 & 1.56 & $6.32 \times 10^{-12}$ \\
922 & 1.51 & $6.85 \times 10^{-12}$ \\
939 & 1.38 & $7.11 \times 10^{-12}$ \\
980 & 1.31 & $7.78 \times 10^{-12}$ \\
1055 & 1.28 & $9.10 \times 10^{-12}$ \\
1169 & 1.27 & $1.13 \times 10^{-11}$ \\
1266 & 1.17 & $1.35 \times 10^{-11}$ \\
1340 & 1.12 & $1.52 \times 10^{-11}$
\end{tabular}


Table 7. Sums of the rate constants for the evaluation of equalities given by Eq. (14) and (15).

\begin{tabular}{ccccccc}
\hline & \multicolumn{2}{c}{$10^{11} \times k\left(\mathrm{~cm}^{3}\right.$ molecule $\left.^{-1} \mathrm{~s}^{-1}\right)$} & & \multicolumn{2}{c}{$10^{11} \times k\left(\mathrm{~cm}^{3}\right.$ molecule $\left.^{-1} \mathrm{~s}^{-1}\right)$} & \\
\cline { 2 - 3 }$T(\mathrm{~K})$ & $k_{\mathrm{II}}$ & $0.5\left(k_{\mathrm{III}}+k_{\mathrm{I}}\right)$ & Error $(\%)$ & $k_{\mathrm{VI}}+\mathrm{k}_{\mathrm{V}}$ & $k_{\mathrm{IV}}+k_{\mathrm{I}}$ & Error (\%) \\
\hline 900 & 0.781 & 0.76 & 2.6 & 1.38 & 1.39 & 2 \\
1000 & 1.01 & 0.994 & 1.7 & 1.814 & 1.87 & 3.2 \\
1100 & 1.248 & 1.24 & 0.89 & 2.26 & 2.3 & 1.5 \\
1200 & 1.48 & 1.48 & 0.22 & 2.72 & 2.76 & 1.4 \\
1300 & 1.72 & 1.73 & 0.53 & 3.19 & 3.23 & 1.28 \\
1400 & 1.96 & 1.98 & 0.86 & 3.64 & 3.69 & 1.2
\end{tabular}


Table 8. Summary of rate constants for $\mathrm{H}$ and $\mathrm{D}$ abstractions by $\mathrm{OH}$ from alkenes according to the expression $A \exp ^{(-B / T)} \mathrm{cm}^{3}$ molecule $\mathrm{e}^{-1}$. The first six rate constant listings are for propene and the last 3 are for butene.

\begin{tabular}{ccc}
\hline Site-specific rate constant & $A$ & $B$ \\
$k_{3, \mathrm{H}}$ & $2.32 \times 10^{-11}$ & 2341 \\
$k_{3, \mathrm{D}}$ & $1.96 \times 10^{-11}$ & 2420 \\
$k_{1, \mathrm{H}}$ & $1.39 \times 10^{-11}$ & 2270 \\
$k_{1, \mathrm{D}}$ & $1.95 \times 10^{-11}$ & 2868 \\
$k_{2, \mathrm{H}}$ & $7.2 \times 10^{-12}$ & 2382 \\
$k_{2, \mathrm{D}}$ & $7.695 \times 10^{-12}$ & 2575 \\
$k_{3}$ & $2.47 \times 10^{-11}$ & 1534 \\
$k_{2, \text { trans }}$ & $2.27 \times 10^{-10}$ & 4350 \\
$k_{2, \text { cis }}$ & $6.29 \times 10^{-11}$ & 3334
\end{tabular}


Table 9. Comparison between experimental and theoretical branching ratios for the three $\mathrm{H}$ abstraction by $\mathrm{OH}$ channels of propene. The reported values for the branching ratios $(\phi)$ are given in percentage.

\begin{tabular}{|c|c|c|c|c|c|c|c|c|c|c|c|c|}
\hline \multirow{2}{*}{$T(\mathrm{~K})$} & \multicolumn{9}{|c|}{$\phi_{\text {RIa }}$} & \multicolumn{6}{c|}{$\phi_{\text {RIb }}$} & \multicolumn{3}{c|}{$\phi_{\text {RIc }}$} \\
\cline { 2 - 13 } & $\begin{array}{c}\text { this } \\
\text { work }\end{array}$ & ref $^{5}$ & ref $^{4}$ & ref $^{25}$ & $\begin{array}{c}\text { this } \\
\text { work }\end{array}$ & ref $^{5}$ & ref $^{4}$ & ref $^{25}$ & $\begin{array}{c}\text { this } \\
\text { work }\end{array}$ & ref $^{5}$ & ref $^{4}$ & ref $^{25}$ \\
\hline 800 & 64.7 & 81.5 & 71.5 & 82.1 & 7.2 & 8.5 & 24.8 & 9.7 & 28.1 & 10 & 3.7 & 8.2 \\
\hline 900 & 64.8 & 79.9 & 68.1 & 79.6 & 7.2 & 8.9 & 27.2 & 10.6 & 28 & 11.2 & 4.7 & 9.8 \\
\hline 1000 & 65 & 78.5 & 65.7 & 77.2 & 7.1 & 9.2 & 28.9 & 11.4 & 27.9 & 12.3 & 5.4 & 11.4 \\
\hline 1100 & 65.1 & 77.4 & 63.9 & 75.3 & 7.1 & 9.4 & 30.1 & 12 & 27.8 & 13.2 & 6.0 & 12.7 \\
\hline 1200 & 65.3 & 76.2 & 62.6 & 73.5 & 7.0 & 9.6 & 30.9 & 12.5 & 27.7 & 14.2 & 6.5 & 14.0 \\
\hline 1300 & 65.4 & 75.2 & 61.8 & 71.9 & 7.0 & 9.8 & 31.3 & 13.0 & 27.6 & 15 & 6.9 & 15.1 \\
& & & & & & & & & & & & \\
\hline 1400 & 65.5 & 74.3 & 61.3 & 70.5 & 7.0 & 9.9 & 31.6 & 13.4 & 27.5 & 15.8 & 7.1 & 16.1 \\
& & & & & & & & & & & & \\
\hline
\end{tabular}




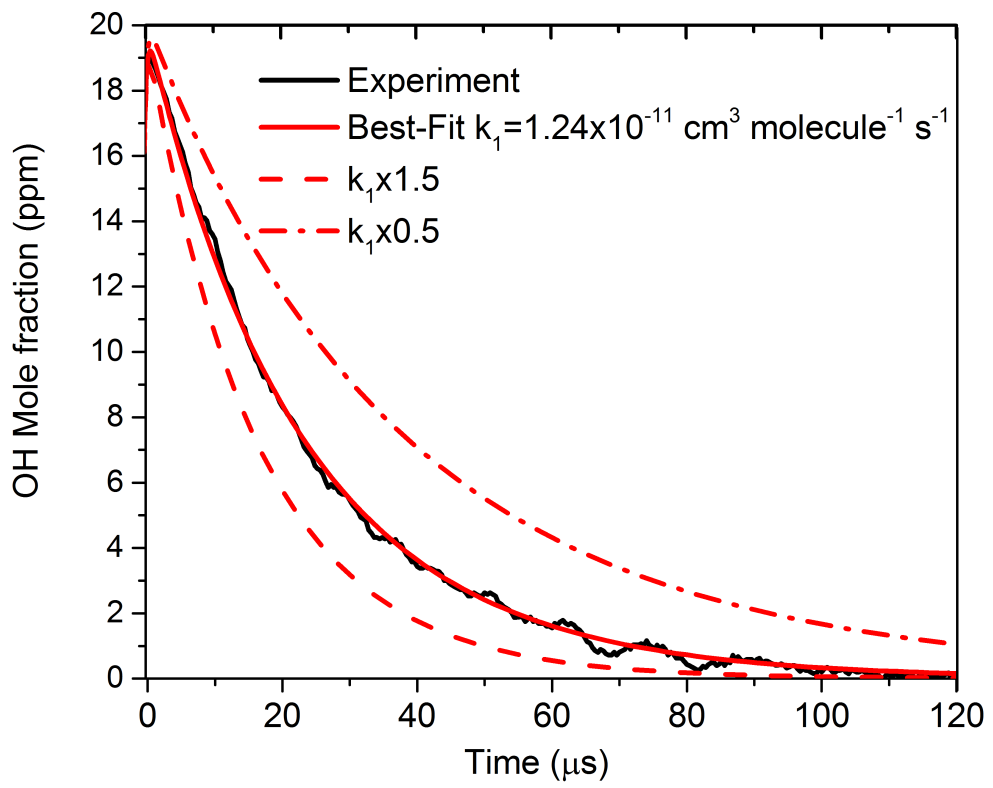

Fig. 1. Propene $+\mathrm{OH}$ reaction rate measurements at $1101 \mathrm{~K}$ and $1.38 \mathrm{~atm}$. The best-fit simulated profile and perturbations of $\pm 50 \%$ are also presented. 


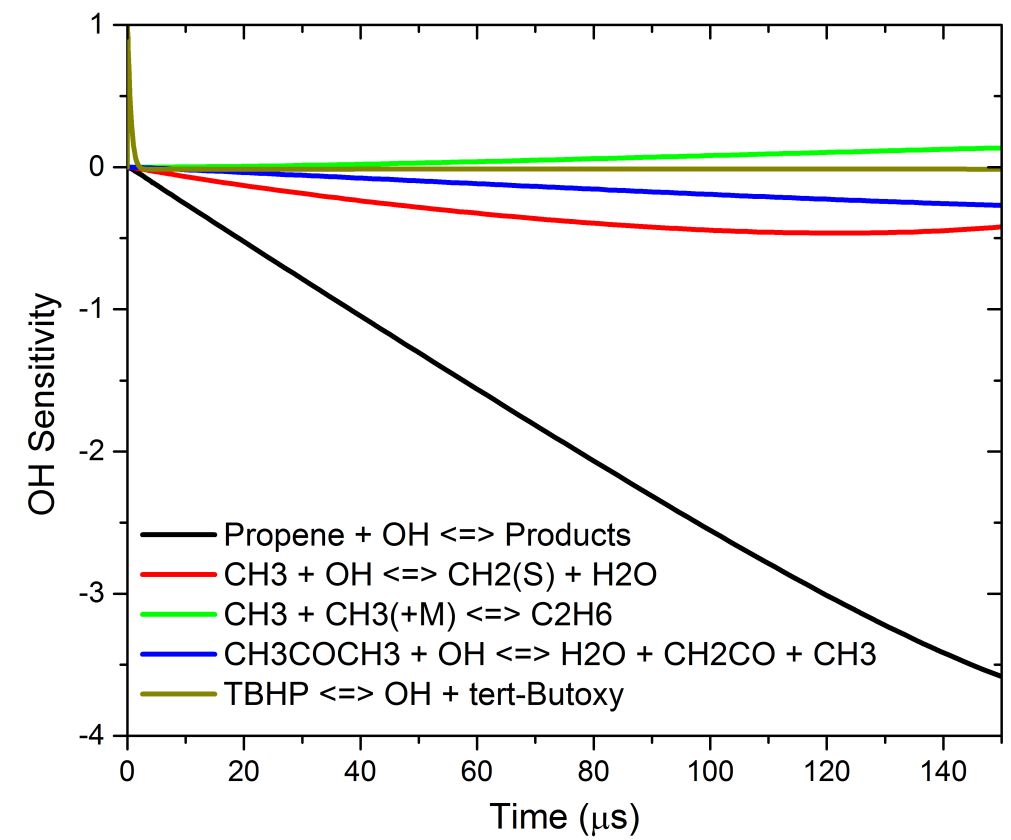

Fig. 2. $\mathrm{OH}$ sensitivity of the rate coefficient measurements for propene $+\mathrm{OH}$ at $1101 \mathrm{~K}$ and $1.38 \mathrm{~atm}$. Initial mixture: $312 \mathrm{ppm}$ propene, $19 \mathrm{ppm}$ TBHP (60 ppm water), balance Ar. 


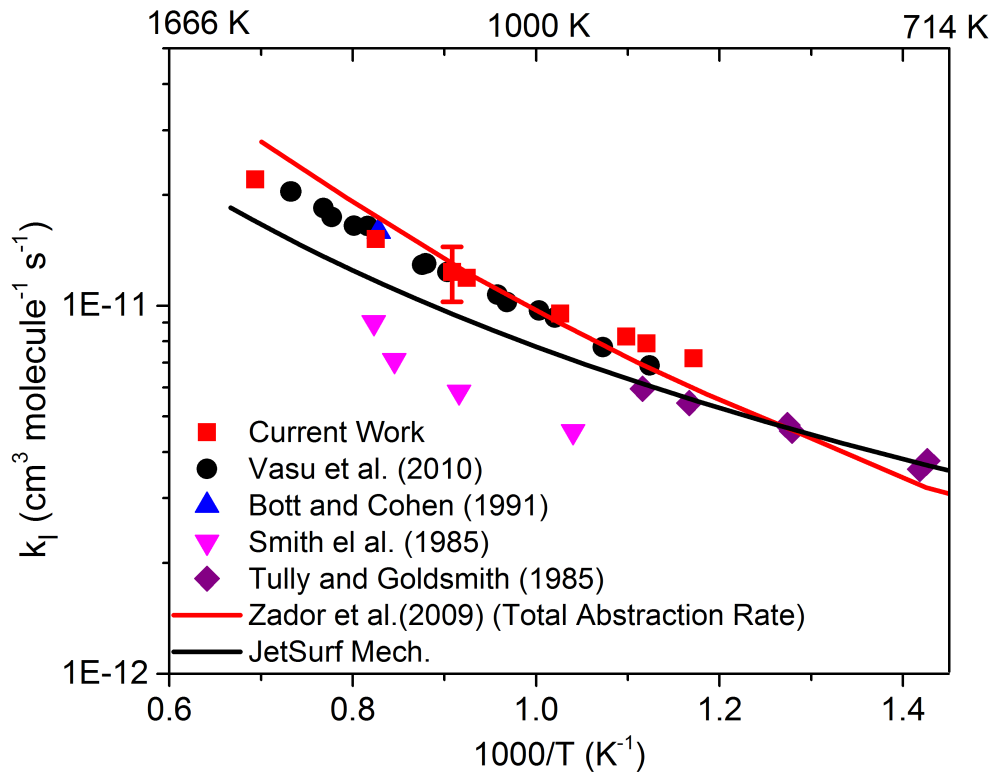

Fig. 3. Arrhenius plot of the rate coefficients for propene $+\mathrm{OH}=>$ products. 


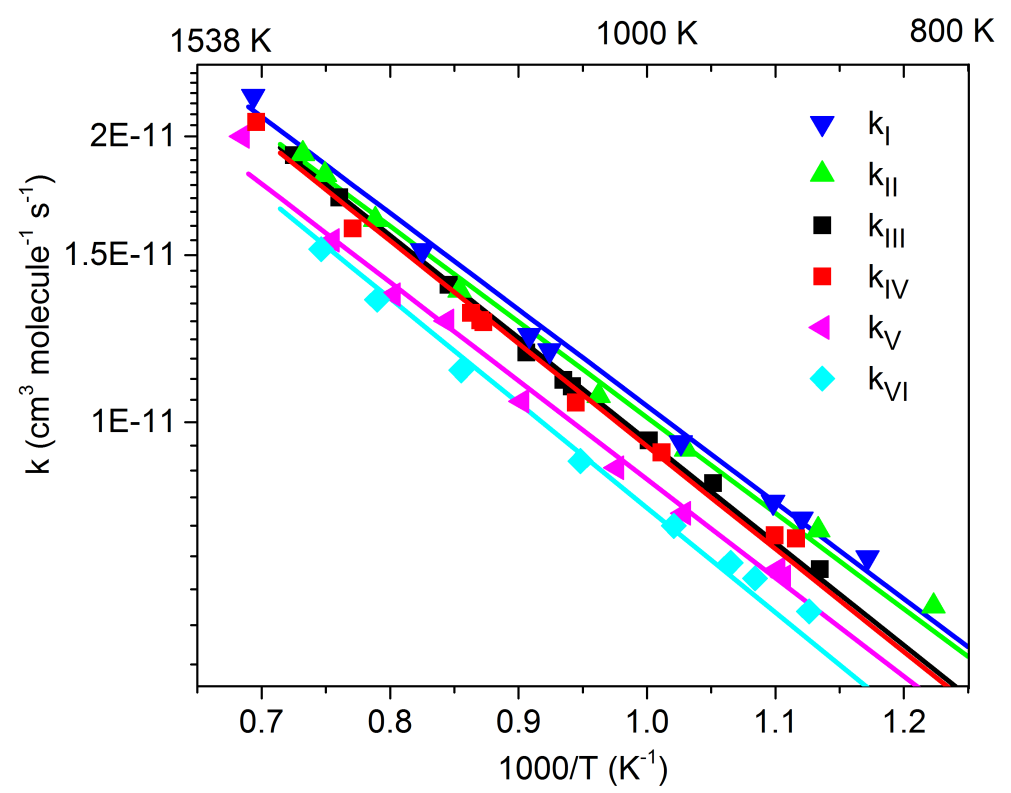

Fig. 4. Arrhenius plot of the rate coefficients for propene isotopes $+\mathrm{OH}=>$ products. 


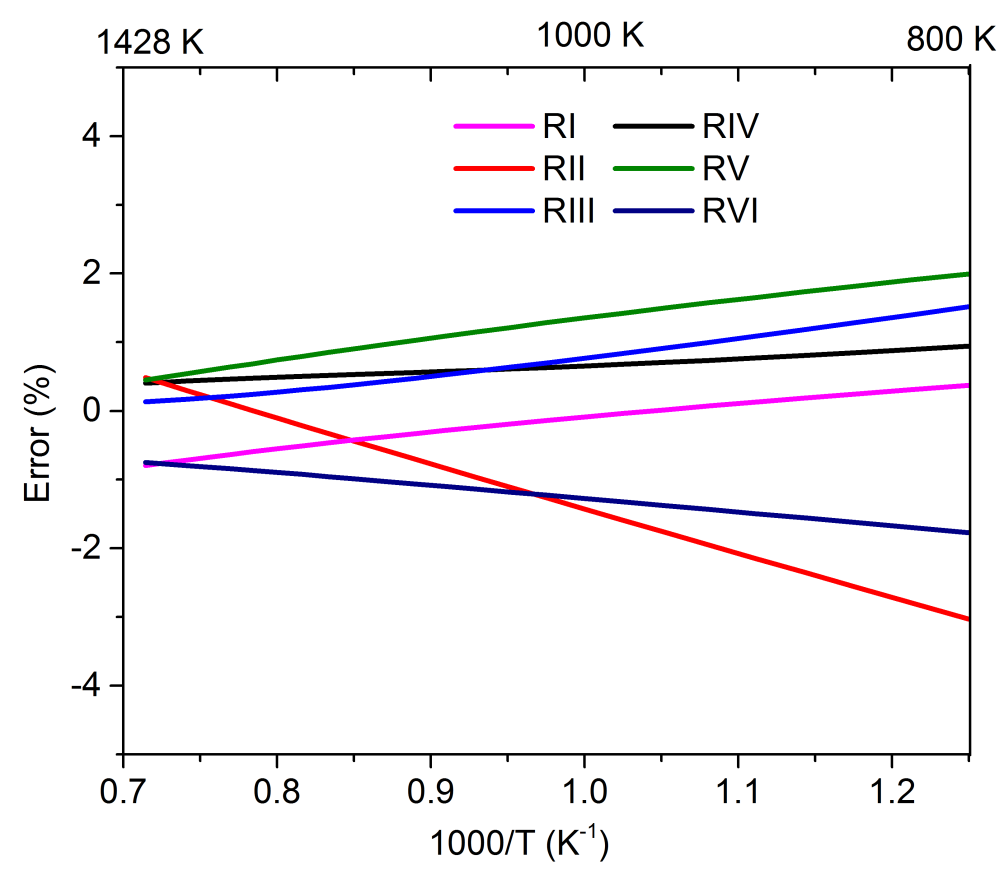

Fig. 5: Percentage error between the calculated and measured overall rate coefficients. 


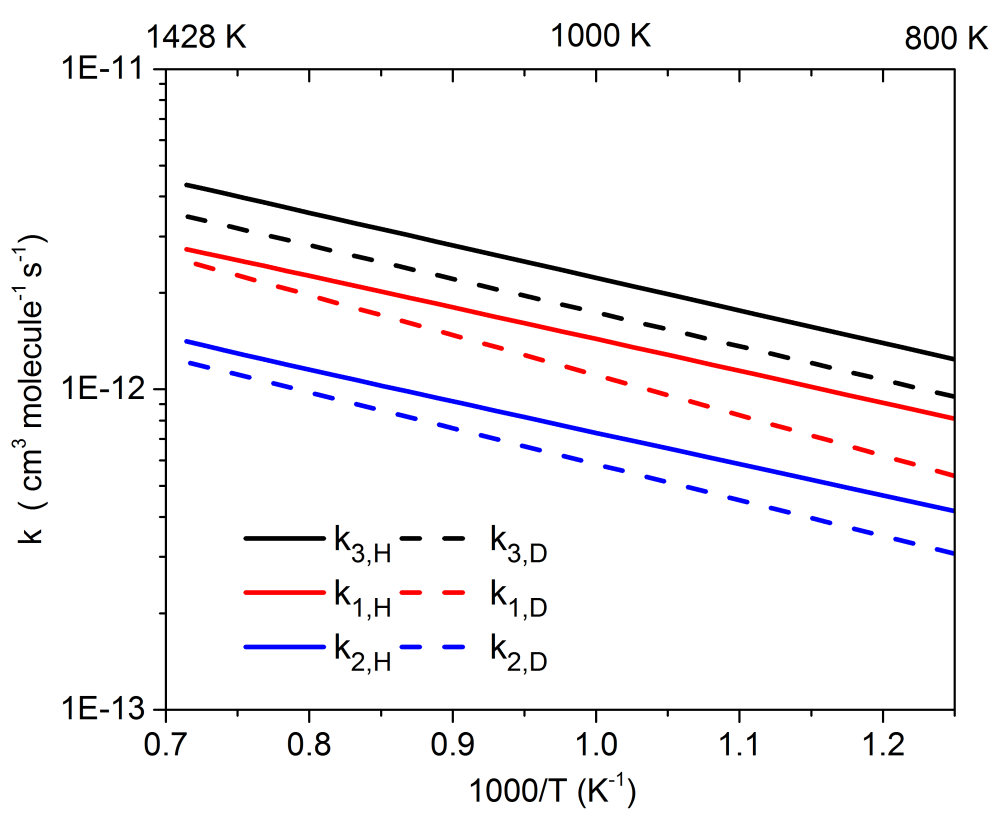

Fig. 6: Site-specific rate coefficients for $\mathrm{H}$ and $\mathrm{D}$ abstraction from propene by $\mathrm{OH}$ radicals. 


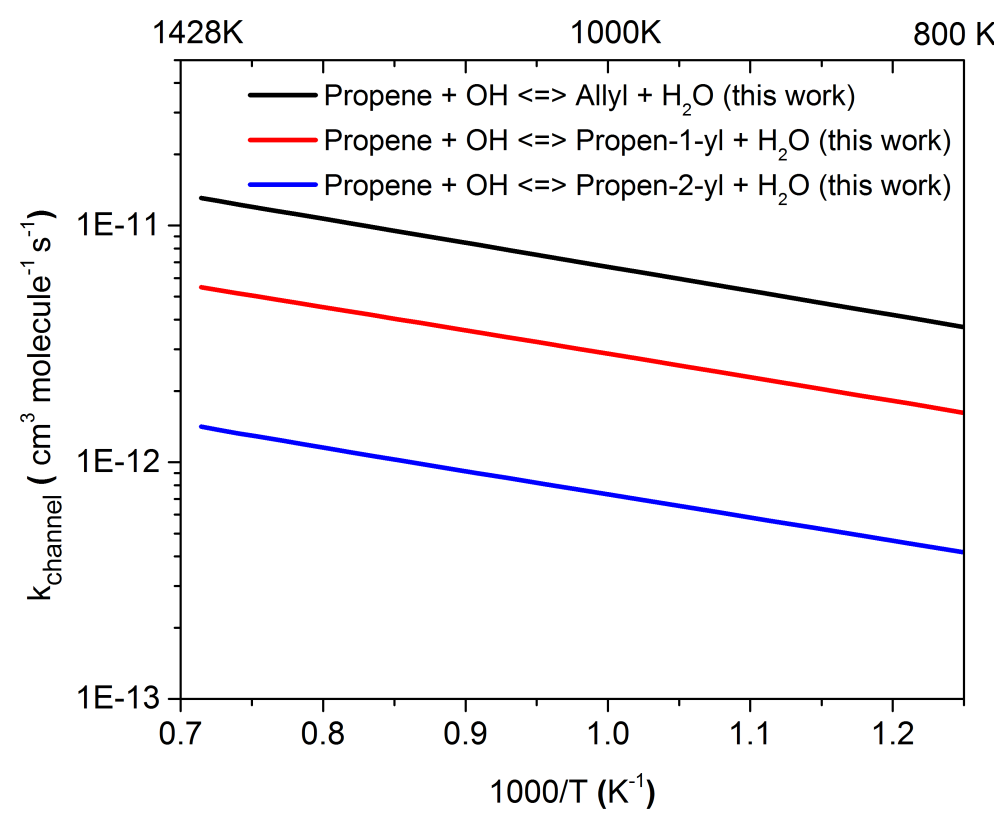

Fig. 7. Total rate coefficients for the three $\mathrm{H}$ abstraction channels of propene. 


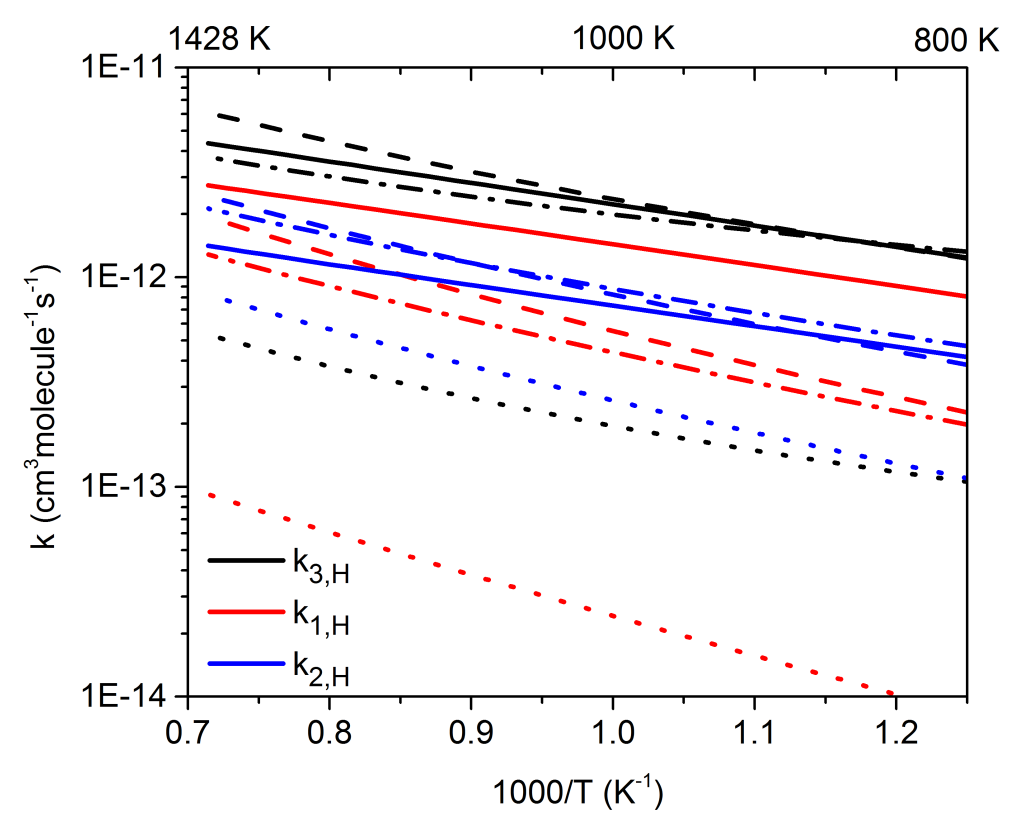

Fig. 8. Comparison of site-specific rate coefficients for $\mathrm{H}$ abstraction by $\mathrm{OH}$ from propene.

Solid lines: current work. Dashed lines: Zádor et al. (2009) ${ }^{5}$. Dash-dotted lines: Tsang (1991) ${ }^{25}$. Dotted lines: Zhou et al. (2009) ${ }^{4}$. 


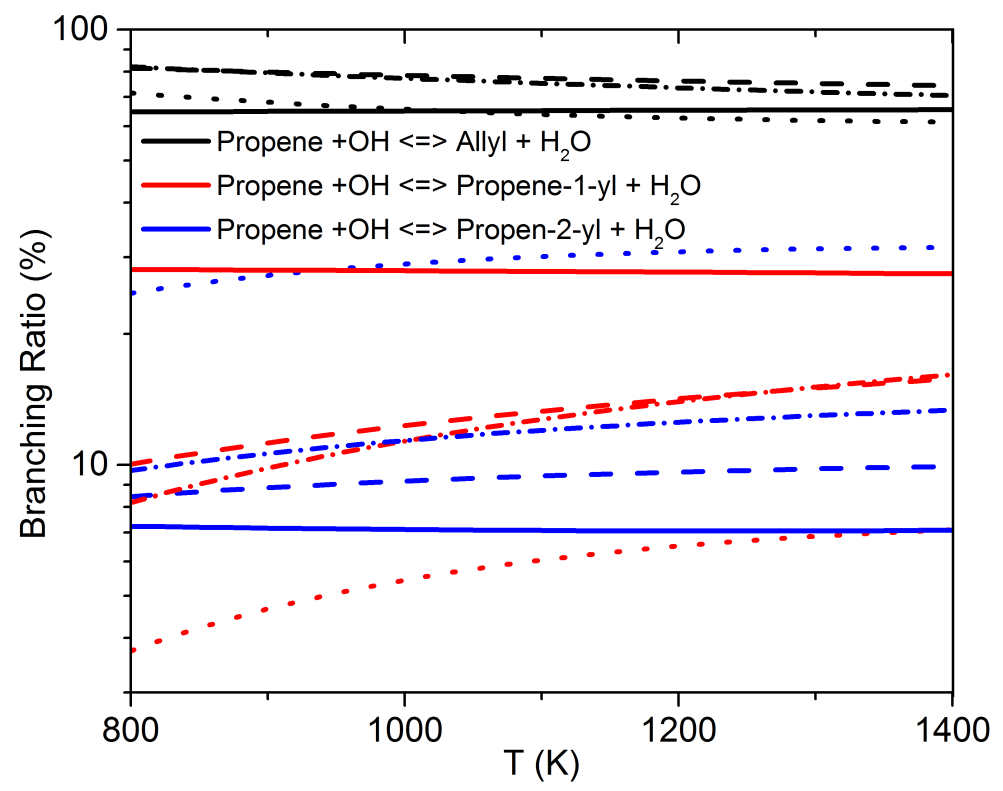

Fig. 9. Branching ratios of the $\mathrm{H}$ abstraction channels. Solid lines: current work. Dashed lines:

Zádor et al. (2009) ${ }^{5}$. Dash-dotted lines: Tsang $(1991)^{25}$. Dotted lines: Zhou et al. (2009) ${ }^{4}$. 